\title{
From integral experiments to nuclear data improvement
}

\author{
A. Santamarina \\ CEA Cadarache, DEN/DER/SPRC, 13108 Saint-Paul-lez-Durance Cedex, France
}

\begin{abstract}
Target accuracy on LWR neutronics parameters is 2 to 5 times lower than the a priori uncertainty $(1 \sigma)$ due to nuclear data. This paper summarizes the experimental facilities and the integral measurements that are required for code qualification. The rigorous use of integral information through trend analysis method is described. Trends on JEF2 data from Keff measurements and P.I.Es are presented. These trends were accounted for in the new JEFF3 evaluations. The role of fundamental experiments, such as worth measurement of separated isotopes, is emphasized. Some recent improvements in JEFF3.1 $\left({ }^{237} \mathrm{~Np},{ }^{239} \mathrm{Pu}\right)$ are extracted from these specific experiments.
\end{abstract}

\section{Introduction}

The main objectives of the Validation/Qualification process for neutronics code package are:

- the code validation against reference calculations,

- the code qualification against integral experiments,

- the "calibration" of errors in a specified use range,

- the ability to improve the next code package, in order to meet the design target accuracy.

To achieve these goals, on one hand clean-precise-exhaustive integral experiments are needed, and on the other hand a rigorous $\mathrm{V} \& \mathrm{~V} \& \mathrm{Q}$ methodology is required. Therefore, $\mathrm{C} / \mathrm{E}$ disagreement is linked to nuclear data errors, and statistical adjustment can be implemented. Trend analysis enables the feedback to evaluators, and improvement of evaluations in international data files is carried out. The example of the improvement of the European JEFF File is presented below.

\section{The V\&V\&Q method}

The Verification/Validation/Qualification process contains three successive steps [1]:

- The first step verifies through unitary tests that numerical models and programming of each module are correct.

- The second step is required in deterministic codes to assess the calculation biases induced by the physical approximations in the Boltzmann equation. First, the Validation of the code functionalities is carried out (Pij, resonance selfshielding, MOC flux, depletion, accurate homogenization, Sn, etc.). Then, the "Reference calculation scheme", used in integral experiment analysis, is validated. This validation is based on the comparison to reference calculations (continuous-energy Monte Carlo), using the same nuclear data library. Thus, the validation process enables the "calibration" of the "Reference scheme": the calculation bias is determined for each reaction rate and LWR design parameters.

- The Qualification corresponds to the comparison of the results of the global package (code + "Reference scheme"
+ nuclear data library) against experimental results from integral measurements. This third step allows the derivation of the scaling factor and the posterior uncertainty on commercial-reactor design parameter [2] (representativeness method [3]). From $\mathrm{C} / \mathrm{E} \pm \delta \mathrm{E}$ values and covariance matrices, a statistical adjustment of nuclear data can also be carried out to feedback integral information to evaluators.

\section{Target accuracy and ND uncertainty on LWR parameters}

Target-accuracies on LWR parameters are generally defined by reactor designers and Utilities.

The a priori uncertainty due to nuclear data in the calculated value of parameter $\mathrm{R}$ can be obtained from the covariance matrix $D$ and the sensitivity vector $S_{R}$ :

$$
\Delta \mathrm{R}^{2}=\mathrm{S}_{\mathrm{R}}^{+} \mathrm{D} \mathrm{S}_{\mathrm{R}}
$$

with $\mathrm{S}_{\mathrm{R}}^{j}=\sigma^{j} / \mathrm{R} \cdot \mathrm{dR} / \mathrm{d} \sigma^{j}$.

Sensitivity profiles to nuclear data have been obtained from the First Order Perturbation Theory using APOLLO2 [4]. Sensitivity coefficients to cross sections and multiplicities of the main isotopes were derived on the European JEF 15-group structure shown in table 1.

Using reliable nuclear data uncertainties and correlations is of importance for the quality of uncertainty analysis. Correlations between energy groups, cross sections and isotopes should be in principle considered. However, in the most recent libraries, obtaining reliable error information on cross sections is still difficult. Thus, standard deviations and correlations have been estimated using crude techniques [5] (comparison between evaluated files, quick review of cross section measurements, information given by the standard cross section committee and nuclear data compilations).

The comparison of the target-accuracy and the $95 \%$ confident interval linked to nuclear data is shown in table 2 for each LWR design parameter.

Table 2 points out that target-accuracies are 2 to 5 times lower than the a priori uncertainty on the calculated LWR 
Table 1. JEF 15-group mesh for sensitivity/uncertainty analysis.

\begin{tabular}{ccc}
\hline Macrogroup & Upper energy $(\mathbf{e V})$ & Lethargy width \\
\hline 1 & $1.964010^{7}$ & 1.175 \\
\hline 2 & $6.065310^{6}$ & 1.000 \\
\hline 3 & $2.231310^{6}$ & 0.500 \\
\hline 4 & $1.353410^{6}$ & 1.000 \\
\hline 5 & $4.978710^{5}$ & 1.000 \\
\hline 6 & $1.831610^{5}$ & 1.000 \\
\hline 7 & $6.737910^{4}$ & 1.000 \\
\hline 8 & $2.478810^{4}$ & 1.000 \\
\hline 9 & $9.118810^{3}$ & 1.500 \\
\hline 10 & $2.034710^{3}$ & 1.500 \\
\hline 11 & 454.0 & 3.000 \\
\hline 12 & 22.6 & 1.732 \\
\hline 13 & 4.0 & 2.002 \\
\hline 14 & 0.54 & 1.686 \\
\hline 15 & 0.10 & 6.812 \\
\hline
\end{tabular}

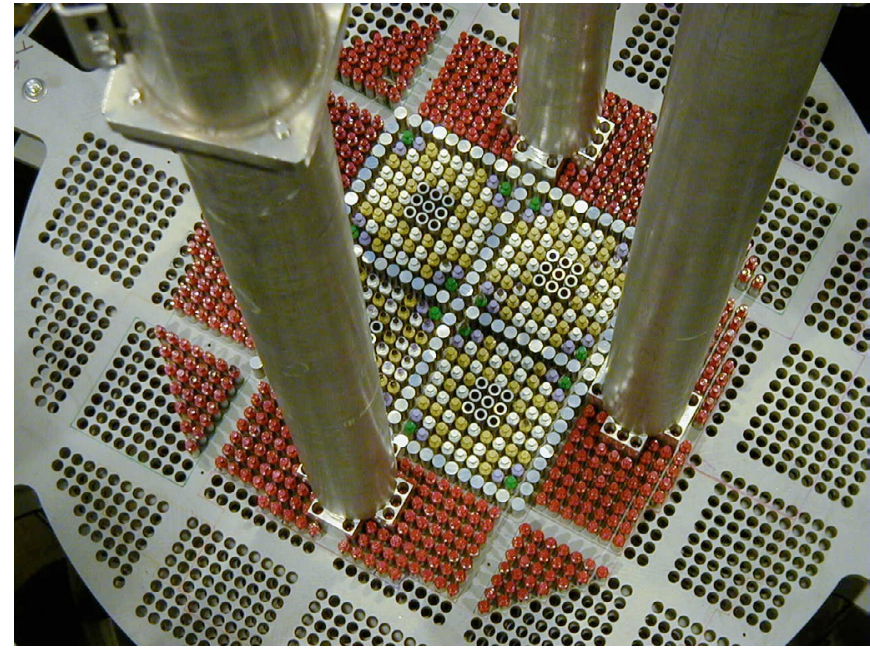

Fig. 1. FUBILA experiment (ABWR-100\% MOX mock-up).

Table 2. TRIPOLI4 analysis of EOLE critical lattices.

\begin{tabular}{ccc}
\hline LWR design parameter & Target-accuracy & Prior uncert. $2 \sigma$ \\
\hline Initial Reactivity & $300 \mathrm{pcm}$ & $1600 \mathrm{pcm}$ \\
\hline Pin-by-pin Power map & $2 \%$ & $4 \%$ \\
\hline Fuel Inventory $(\mathrm{Pu}$ conc) & $2-3 \%$ & $4-9 \%$ \\
\hline Reactivity Loss vs Bu & $2 \%$ & $8 \%$ \\
\hline Pu ageing & $0.02 \mathrm{pcm} / \mathrm{d}$ & $0.10 \mathrm{pcm} / \mathrm{d}$ \\
\hline Doppler Coefficient & $3 \%$ & $15 \%$ \\
\hline Moderator Temp Coeff & $1 \mathrm{pcm} /{ }^{\circ} \mathrm{C}$ & $4 \mathrm{pcm} /{ }^{\circ} \mathrm{C}$ \\
\hline Soluble Boron Coeff & $1 \%$ & $3 \%$ \\
\hline Void Coefficient & $2 \%$ & $6 \%$ \\
\hline Kinetics Parameters & $2 \%$ & $5 \%$ \\
\hline Control-rod Efficiency & $2 \%$ & $5 \%$ \\
\hline Efficiency LBP $(\mathrm{Gd}, \mathrm{Er})$ & $2 \%$ & $6 \%$ \\
\hline
\end{tabular}

parameter. Therefore, integral experiments are required to meet the design requirements.

\section{Integral experiments required for qualification}

Four types of experiments are needed to achieve the Qualification process:

\subsection{Mock-up experiments}

In France, mock-up experiments are performed at CEACadarache in the EOLE and MASURCA zero-power reactors: critical LWR cores and FBR cores are respectively studied. CAMELEON and EPICURE experiments are PWR mock-ups, ERASME configurations simulate High Conversion Reactors, MISTRAL4 core is a APWR-100\% MOX core, BASALA and FUBILA configurations are respectively BWR and ABWR mock-ups (fig. 1).

For example, EPICURE/UMZONE configuration is a PWR mixed-loading core mock-up (UOX-3.7\% ${ }^{235} \mathrm{U}$ and MOX $17 \times 17$ assemblies), which enabled the qualification of the power map challenging calculation. Figure 2 points out

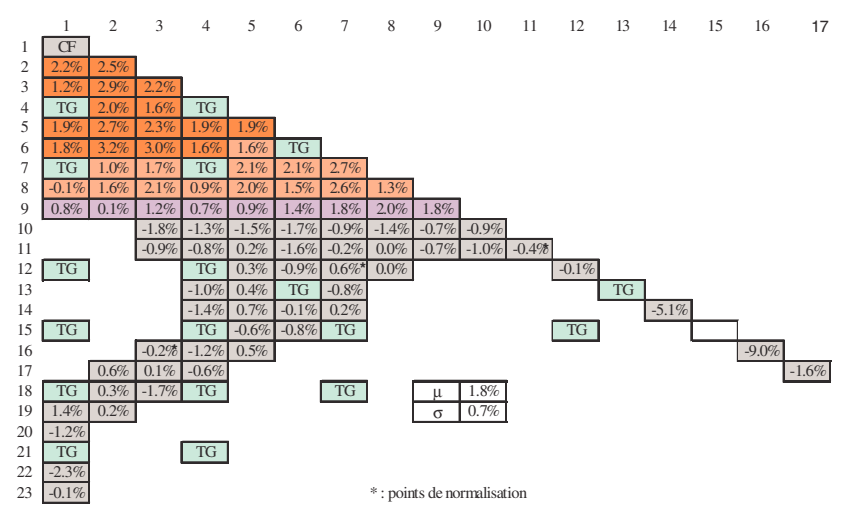

Fig. 2. C/E comparison in EPICURE (UOX:grey - MOX:red-pink).

that APOLLO2 "CEA-97" reference scheme is able to predict the measured pin-by-pin fission rate within $3 \%$ accuracy.

MISTRAL2 and MISTRAL3 are regular MOX-7\% Pu cores, which allowed the qualification of Keff and reactivity coefficients (Soluble Boron, Temperature and Void coeff.); Kinetics parameters and Absorber Worth were also measured in these MOX lattices. MISTRAL1 (fig. 3) is a regular core that enabled the same qualification for LWR-UOX fuel.

\subsection{Chemical assays on Irradiated fuels}

This kind of experimental information aims to validate fuel depletion calculation. U, Pu, Am, cm and main FPs concentrations are check against chemical analyses carried out on fuel rod cuts from commercial reactors. $\mathrm{Nd}$ isotopics and ${ }^{148} \mathrm{Nd} /{ }^{238} \mathrm{U}$ experimental ratio allows the accurate determination of the fuel sample burn-up. The example of the P.I.E. programme in the French PWR-900Mwe Gravelines is given in figures 4 and 5: the two experimental assemblies enable the qualification of the fuel inventory prediction from 20 up to $60 \mathrm{GWd} / \mathrm{t}$ (2 to 5 irradiation cycles).

The C/E comparison based on JEF2 library for the samples located at mid-height of these assemblies is summarized in table 3 for the major actinide concentrations [6]. 


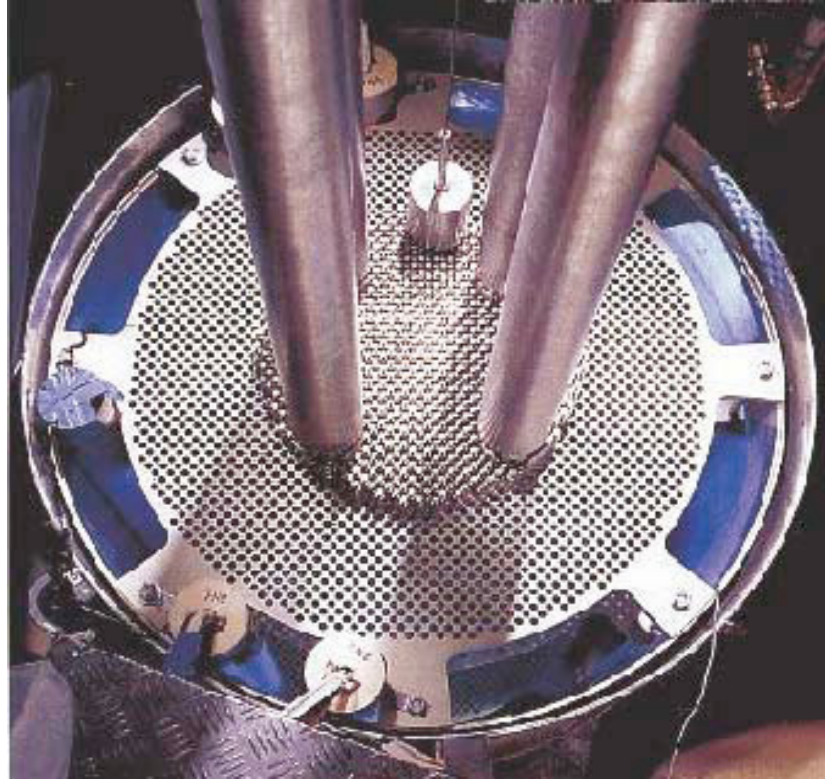

Fig. 3. MISTRAL1 UOX-3.7\% ${ }^{235} \mathrm{U}$ core.

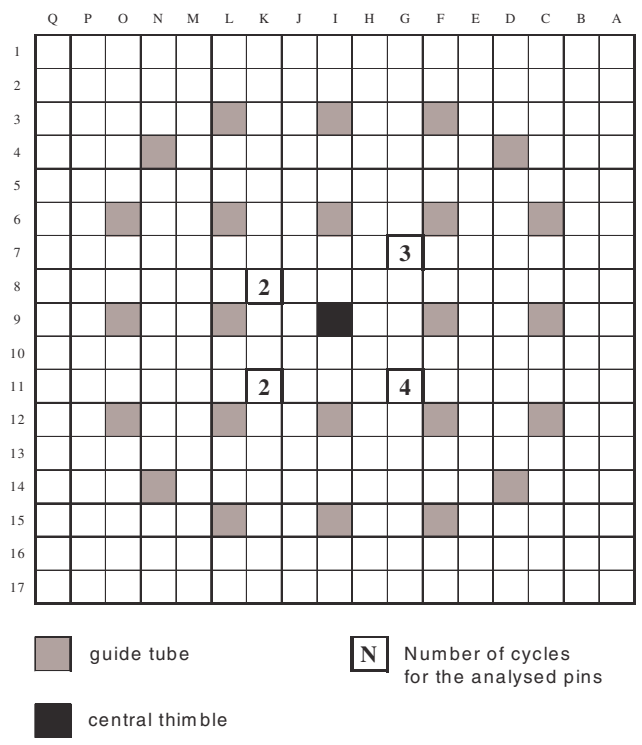

Fig. 4. Analysed pins in the assembly Gra-FF06E2BV.

\subsection{Reactivity loss with burn-up}

Reactor Cycle Length is one of the major design parameter. Thus, specific experiments devoted to spent fuel reactivity worth measurements are required. In French P.I.E. programmes, specific rod cuts $(10 \mathrm{~cm})$ are extracted from the irradiated pin, close to the "chemical assay" rod cut $(2 \mathrm{~cm})$, as shown in figure 6. Then, irradiated samples are built from these rod cuts and are oscillated at the centre of the MINERVE test lattice. In order to qualify the reactivity loss versus burnup, for various fuels and spectra, several test lattices are available: Mélodie-LWR (fig. 7), Mélodie-MOX, MorganeHCR, Ermine-FBR.

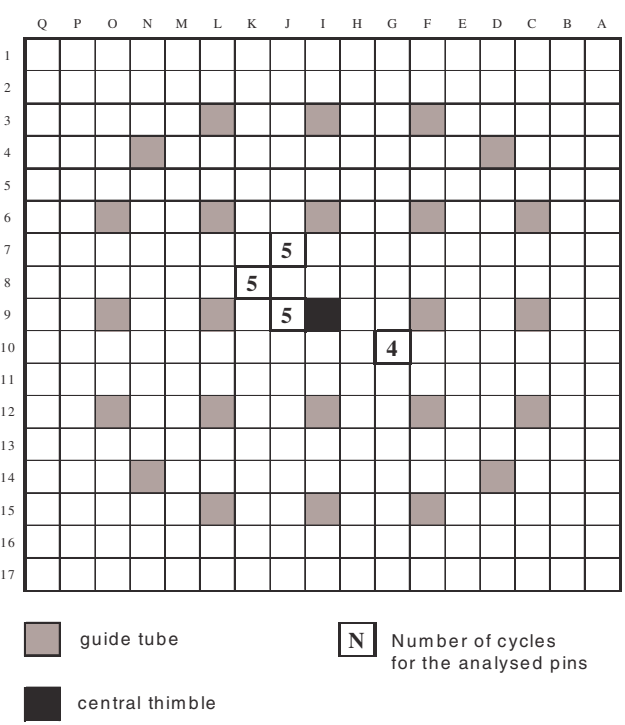

Fig. 5. Analysed pins in the assembly Gra-FF06E3BV.

Table 3. Calculation-Experiment biases (\%) on PWR-Gra P.I.E.

\begin{tabular}{lrrrrr}
\hline Cycle / N ${ }^{\circ}$ Pin & $2 / \mathrm{K} 08$ & $3 / \mathrm{G} 07$ & $4 / \mathrm{G} 10$ & $5 / \mathrm{K} 08$ & $5 / \mathrm{J} 09$ \\
\hline Burnup (GWd/t) & 26 & 38 & 50 & 60 & 60 \\
\hline $\mathrm{U} 234 / \mathrm{U} 238$ & $-0.2 \%$ & $-1.0 \%$ & $0.9 \%$ & $1.3 \%$ & $0.9 \%$ \\
\hline $\mathrm{U} 235 / \mathrm{U} 238$ & $0.4 \%$ & $2.5 \%$ & $2.1 \%$ & $-1.9 \%$ & $5.9 \%$ \\
\hline $\mathrm{U} 236 / \mathrm{U} 238$ & $-4.1 \%$ & $-4.6 \%$ & $-4.3 \%$ & $-3.9 \%$ & $-4.1 \%$ \\
\hline $\mathrm{Np} 237 / \mathrm{U} 238$ & $-2.3 \%$ & $-3.7 \%$ & $-5.3 \%$ & - & $-6.4 \%$ \\
\hline $\mathrm{Pu} 238 / \mathrm{U} 238$ & $-9.1 \%$ & $-10.6 \%$ & $-9.6 \%$ & $-9.5 \%$ & $-9.2 \%$ \\
\hline $\mathrm{Pu} 239 / \mathrm{U} 238$ & $-0.4 \%$ & $0.4 \%$ & $0.2 \%$ & $-0.6 \%$ & $2.5 \%$ \\
\hline $\mathrm{Pu} 240 / \mathrm{U} 238$ & $-1.5 \%$ & $-2.1 \%$ & $-0.7 \%$ & $-0.2 \%$ & $-0.8 \%$ \\
\hline $\mathrm{Pu} 241 / \mathrm{U} 238$ & $-3.5 \%$ & $-4.1 \%$ & $-2.9 \%$ & $-3.8 \%$ & $-1.2 \%$ \\
\hline $\mathrm{Pu} 242 / \mathrm{U} 238$ & $-7.0 \%$ & $-9.2 \%$ & $-7.5 \%$ & $-6.6 \%$ & $-7.4 \%$ \\
\hline
\end{tabular}

\subsection{Fundamental experiments}

Fundamental experiments are devoted to the qualification of the nuclear data library of neutronics codes.

- Reaction rates, conversion ratio and spectral indices are measured in regular lattices of critical cores. Table 4 presents the APOLLO2-Experiment comparison on fission rates using CEA miniature fission chambers $(\phi 4 \mathrm{~mm})$; various spectra were investigated in these MOX lattices from MISTRAL2 $\mathrm{V}_{\mathrm{H} 2 \mathrm{O}} / \mathrm{V}_{\mathrm{MOX}}=2$ down to moderation ratio $\mathrm{V}_{\mathrm{H} 2 \mathrm{O}} / \mathrm{V}_{\mathrm{MOX}}=0.5$ in ERASME/S experiment.

- Samples of separated isotopes can be investigated. These samples are generally $\mathrm{U}^{\text {nat }} \mathrm{O}_{2}$ pellets doped with a small amount of the separated isotope (1 to $20 \mathrm{mg}$ per pellet). Samples made of 10 pellets are oscillated in MINERVE in order to measure the reactivity worth of the separated isotope: FP isotopes were oscillated in the BUC programme [8], while Actinides are oscillated in the OSMOSE experiment [9]. Furthermore, separated isotope pellets are irradiated in experimental reactors (MELUSINE for thermal-epithermal spectra, PHENIX for fast spectrum), which allows the qualification of the capture cross section from the chemical analysis of the daughter concentration. 


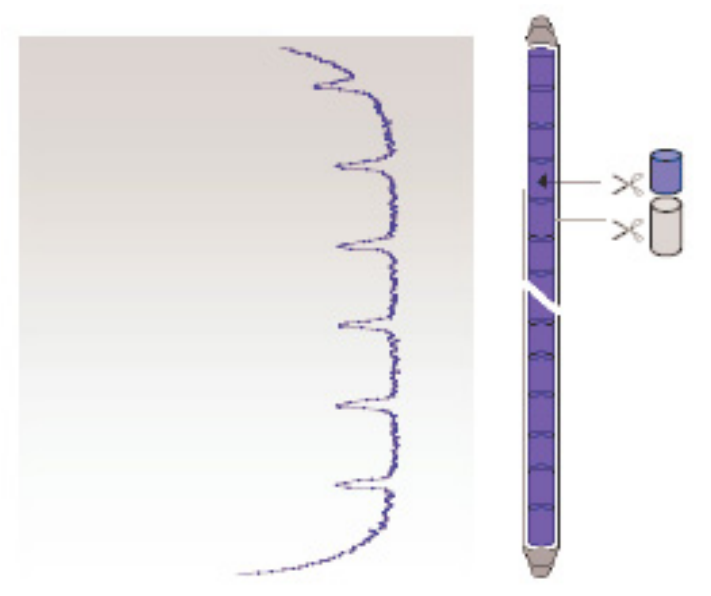

Fig. 6. PWR samples for chemical analysis and Minerve oscillation.

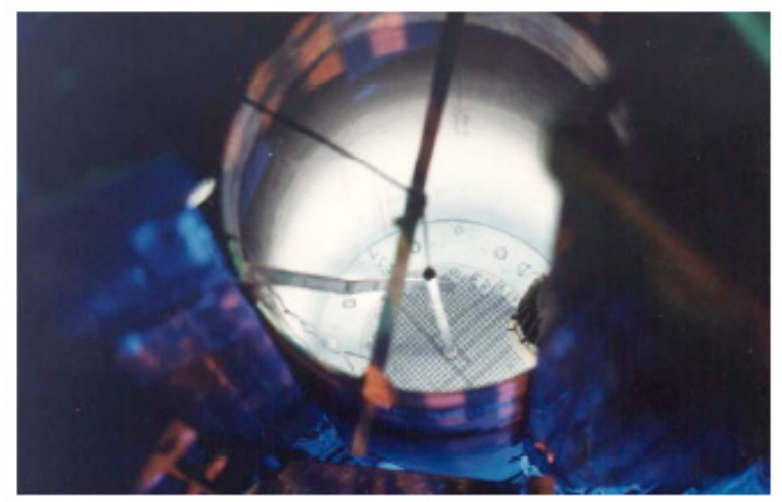

Fig. 7. Sample oscillation in the central cell of Mélodie-LWR.

Table 4. Qualification of JEF2.2 fission cross sections (C/E-1\%).

\begin{tabular}{lllll}
\hline Index & MISTRAL2 & ERASMEL ERASMER ERASMES \\
\hline$\sigma_{\mathrm{f}}^{\mathrm{Pu239}} / \sigma_{\mathrm{f}}^{\mathrm{U} 235}$ & $+2.1 \pm 2$ & $-2.5 \pm 2$ & $-0.4 \pm 2$ & $+0.9 \pm 2$ \\
\hline$\sigma_{\mathrm{f}}^{\mathrm{Pu} 411} / \sigma_{\mathrm{f}}^{\mathrm{Pu} 239}$ & $+0.3 \pm 2$ & $+1.8 \pm 3$ & $+1.3 \pm 3$ & $+4.0 \pm 3$ \\
\hline$\sigma_{\mathrm{f}}^{\mathrm{Pu} 240} / \sigma_{\mathrm{f}}^{\mathrm{Pu} 239}$ & $-3 \pm 4$ & $+7 \pm 4$ & $+8 \pm 4$ & $+12 \pm 5$ \\
\hline$\sigma_{\mathrm{f}}^{\mathrm{Pu} 242} / \sigma_{\mathrm{f}}^{\mathrm{Pu} 239}$ & $+10 \pm 7$ & $+6 \pm 5$ & $+4 \pm 5$ & $-3 \pm 5$ \\
\hline
\end{tabular}

\section{Feedback of integral exp on nuclear data}

Integral data measured in reactors provide relevant information regarding the quality of neutron interaction data. The socalled statistical adjustment method [10] has been extensively used to produce multi-group libraries and improve prediction for the design of reactors. The purpose of the adjustment is to determine optimal modifications of nuclear data (usually group averaged cross sections and neutron multiplicities) through a rigorous mathematical framework in order to minimize the discrepancies between calculated and measured integral parameters. We have developed an improved "Reestimation of Nuclear Data" (code RDN), based on the nonlinear regression method [11].

Traditional adjustment studies are based on reactivity experiments and reaction rate ratio measurements. The originality of our JEF2.2 trend analysis was to take into account $\mathrm{k}_{\mathrm{eff}}$ measurements in UOX and MOX water-moderated lattices,

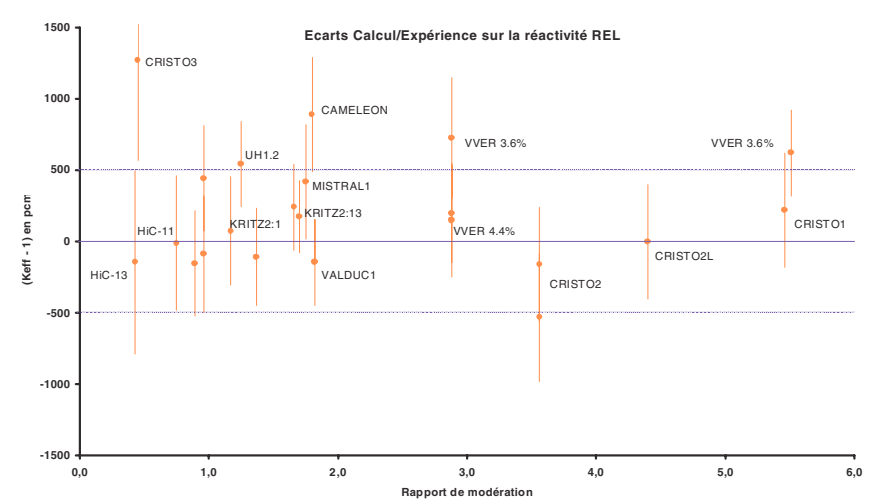

Fig. 8. $\mathrm{C} / \mathrm{E}$ bias on Keff of $\mathrm{LWR}-\mathrm{UO}_{2}$ regular cores.

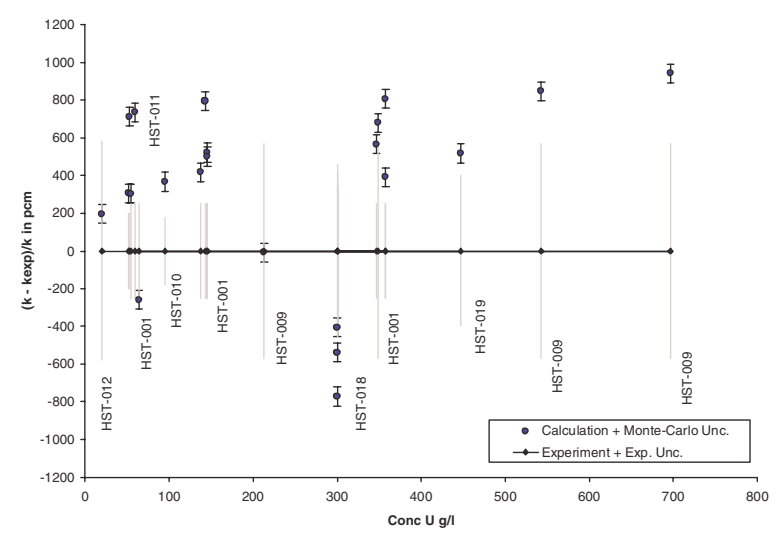

Fig. 9. C/E bias for Highly-Enriched-Uranium Solutions.

as well as highly enriched uranium experiments, but also to include isotopic ratios measured in PWR P.I.Es. Due to their strong sensitivity to $(\mathrm{n}, \gamma)$ cross section, chemical analysis results allow the splitting of $\mathrm{C} / \mathrm{E}$ bias between capture, fission and multiplicity components.

Concerning P.I.E., about $400 \mathrm{C} / \mathrm{E}$ values from UOX and MOX assemblies have been included in the RDN code [11]. Measured actinides are: U234, U235, U236, Np237, Pu238, Pu239, Pu240, Pu241, Pu242, Am241, Am243, cm244 cm245. The selected $\mathrm{k}_{\mathrm{eff}}$ and Buckling measurements in LowEnriched $\mathrm{UO}_{2}$ lattice experiments cover a wide range of moderation ratios. Most of them are LWR-type and have been carried out in EOLE. VVER and HCPWR critical experiments are taken from the International Criticality Safety Database ICSBEP handbook [12]. The C-E bias (in pcm), corresponding to TRIPOLI4 reference calculation using JEF2.2, is plotted in figure 8 .

In order to increase the trend accuracy on the multiplicity $v^{\mathrm{U} 235}$, we used also critical experiments with highly enriched uranium solution $\left(\mathrm{UO}_{2} \mathrm{~F}_{2}+\mathrm{H}_{2} \mathrm{O}\right.$ or $\left.\mathrm{UO}_{2}\left(\mathrm{NO}_{3}\right)_{2}+\mathrm{HNO}_{2}\right)$. We investigated independent experiments from international laboratories involving $\mathrm{U}$ concentration ranging from $20 \mathrm{~g} / \mathrm{l}$ (softer neutron spectrum) up to $700 \mathrm{~g} / 1$ (intermediate neutron spectrum). TRIPOLI4/JEF2 results are shown in figure 9.

JEF2.2 broad group adjustment was performed on the 15-group structure. The quantitative results obtained by the RDN code are gathered in table 5. In this table, the selected nuclear data modifications are considered significant, because the uncertainty after adjustment is stongly reduced and lower 
Table 5. Trends on JEF2 data and JEFF3.1 improvements.

\begin{tabular}{|c|c|c|c|}
\hline Isotope & Xs / E Eange & Estimation RDN & JEFF3.1/JEF2 \\
\hline \multirow[t]{2}{*}{ U235 } & Ig & $+12 \% \pm 3.2 \%$ & $+10 \%$ \\
\hline & nth & $+0.1 \% \pm 0.2 \%$ & $+0.0 \%$ \\
\hline \multirow[t]{4}{*}{ Pu241(n, $\gamma)$} & $\mathrm{E}<0.1 \mathrm{eV}$ & $+0.4 \% \pm 1.5 \%$ & $+1.4 \%$ \\
\hline & {$[0.5 \mathrm{eV}-0.1 \mathrm{eV}]$} & $+7.4 \% \pm 2.6 \%$ & $+7.2 \%$ \\
\hline & {$[4.0 \mathrm{eV}-0.5 \mathrm{eV}]$} & $+0.8 \% \pm 7 \%$ & $+1.5 \%$ \\
\hline & {$[23 \mathrm{eV}-4 \mathrm{eV}]$} & $+11 \% \pm 9 \%$ & $+8.4 \%$ \\
\hline \multirow[t]{2}{*}{ U238 } & Igeff & $-0.6 \% \pm 1.5 \%$ & $-0.6 \%$ \\
\hline & $(n, 2 n)$ & $+6.3 \% \pm 2.1 \%$ & $+10 \%$ \\
\hline
\end{tabular}

than the data modification. Table 5 points out that these trends are consistent with the modifications performed in JEFF3.1 to improve the JEF2.2 evaluations.

The need for increasing JEF2 ${ }^{235} \mathrm{U}$ capture resonance integral [13] is quantified: $+12 \% \pm 3 \%(1 \sigma)$; thus the LealDerrien evaluation [14] was adopted in JEFF3, that allows the cancellation of the longstanding underestimation of ${ }^{236} \mathrm{U}$ build-up (see table 3). Multiplicity thermal value $v_{\text {th }}=2.437$ is confirmed within $0.2 \%$ accuracy.

An accurate trend is shown for the ${ }^{241} \mathrm{Pu}$ epithermal capture: the capture integral of the $0.26 \mathrm{eV}$ resonance in JEF2 needs to be increased by $7.4 \% \pm 2.6 \%(1 \sigma)$. This correction, arising from the underestimation of the ${ }^{242} \mathrm{Pu}$ build-up, was investigated in the framework of a CEA-ORNL collaboration and corrected in JEFF3 with a new evaluation [15].

A reduction by $-0.6 \%$ of the ${ }^{238} \mathrm{U}$ shielded capture cross section in the resolved range is suggested but this small modification is in the uncertainty of this data (a posteriori standard deviation $\pm 1.5 \%$ ); however, considering the importance of this data for Keff and ${ }^{239} \mathrm{Pu}$ build-up calculations, this result was accounted for in the new evaluation of ${ }^{238} \mathrm{U}$ resonance range for JEFF3.1 [16].

\section{The role of specific experiments}

Fundamental experiments based on separated isotopes supply direct information on nuclear data. For example, the reactivity worth measurement of separated poisoning FP nuclides in MINERVE oscillations gives accurate information on capture cross section. The JEF2 calculation of FP sample worth [17] is summarized in table 6.

This $\mathrm{C} / \mathrm{E}$ comparison pointed out the following JEF2 trends, taken into account in the new JEFF3 evaluations [18]:

- ${ }^{149} \mathrm{Sm}(\mathrm{n}, \gamma)$ is underestimated by $-5 \% \pm 2 \%$, so $\Gamma_{n}\left(\mathrm{E}_{\mathrm{R}}=\right.$ $0.1 \mathrm{eV}$ ) was increased by $3 \%$,

- ${ }^{143} \mathrm{Nd}(\mathrm{n}, \gamma)$ is underestimated by $-5 \% \pm 2 \%$, so $\Gamma_{n}$ (bound level) was increased by $4 \%$,

- ${ }^{133} \mathrm{Cs}(\mathrm{n}, \gamma)$ is overestimated by $+7 \% \pm 2 \%$, so accurate resonance parameters from Nakajima measurements [19] were adopted,

- ${ }^{103} \mathrm{Rh}(\mathrm{n}, \gamma)$ is overestimated by $+10 \% \pm 3 \%$, so differential measurements were performed at Gelina Linac and a new evaluation was carried out [20].

These JEFF3 evaluations were checked against FP oscillation experiments and chemical assays on PWR spent fuels: this FP qualification gave satisfactory C-E comparison [21].
Table 6. C/E biases (\%) on FP worth in Minerve lattices.

\begin{tabular}{llll}
\hline FP & Mass $($ g) & LWR: R1-UO & Thermal: R2-UO \\
\hline Sm & 0.026 & $-4.5 \% \pm 2.9 \%$ & $-3.3 \% \pm 3.6 \%$ \\
\hline${ }^{149} \mathbf{S m}$ & 0.004 & $-6.0 \% \pm 2.9 \%$ & $-4.9 \% \pm 3.6 \%$ \\
${ }^{147} \mathbf{S m}$ & 1.008 & $+1.3 \% \pm 4.3 \%$ & $+2.7 \% \pm 4.7 \%$ \\
\hline${ }^{152} \mathbf{S m}$ & 0.586 & $-1.6 \% \pm 2.9 \%$ & $-1.8 \% \pm 3.7 \%$ \\
\hline $\mathbf{N d}$ & 3.602 & $+0.4 \% \pm 3.0 \%$ & $-3.3 \% \pm 3.7 \%$ \\
\hline${ }^{143} \mathbf{N d}$ & 0.574 & $-7.1 \% \pm 3.1 \%$ & $-8.5 \% \pm 3.8 \%$ \\
${ }^{145} \mathbf{N d}$ & 2.325 & $+0.4 \% \pm 3.8 \%$ & $+1.1 \% \pm 4.4 \%$ \\
${ }^{155} \mathbf{G d}$ & 0.008 & $-2.5 \% \pm 2.9 \%$ & $-6.1 \% \pm 4.0 \%$ \\
${ }^{153} \mathbf{E u}$ & 0.431 & $-4.2 \% \pm 4.0 \%$ & $-1.3 \% \pm 4.6 \%$ \\
${ }^{99} \mathbf{T c}$ & 2.142 & $+4.1 \% \pm 3.8 \%$ & $+3.4 \% \pm 3.5 \%$ \\
${ }^{95} \mathbf{M o}$ & 3.650 & $-3.1 \% \pm 3.4 \%$ & $-3.7 \% \pm 3.8 \%$ \\
${ }^{133} \mathbf{C s}$ & 3.076 & $+8.5 \% \pm 3.2 \%$ & $+7.6 \% \pm 3.8 \%$ \\
${ }^{133} \mathbf{C s}$ & 2.200 & $+7.6 \% \pm 3.5 \%$ & $+9.3 \% \pm 3.8 \%$ \\
\hline${ }^{103} \mathbf{R h}$ & 0.376 & $+11.0 \% \pm 4.0 \%$ & $+8.0 \% \pm 4.2 \%$ \\
\hline${ }^{109} \mathbf{A g}$ & 0.640 & $-3.6 \% \pm 4.3 \%$ & $-4.5 \% \pm 4.3 \%$ \\
\hline $\mathbf{A g}$ & 1.105 & $-4.7 \% \pm 4.2 \%$ & $+0.3 \pm 4.7 \%$ \\
\hline
\end{tabular}

From specific integral experiments, recent improvements in JEFF3 file were proposed for ${ }^{239} \mathrm{Pu}$ [22] and ${ }^{237} \mathrm{~Np}$ [23].

The oscillation of two ${ }^{237} \mathrm{~Np}$ samples in OSMOSE showed an underestimation by $-8 \%$ and $-13 \% \pm 2 \%(1 \sigma)$ respectively in JEF2.2 and JEFF3.1 calculations [24]. The APOLLO2 calculations, based on JEFF3.1, of PWR chemical assays stressed a strong underestimation of ${ }^{238} \mathrm{Pu}$ build-up $(-8 \% \pm 2 \%)$ : this $\mathrm{C} / \mathrm{E}$ disagreement is due to ${ }^{237} \mathrm{~Np}$ capture underestimation, that is consistent with OSMOSE results. This obvious trend enables the recommendation to adopt a higher thermal value $\sigma^{2200}=185$ barns (162 b in JEFF3.1). Consequently, the ${ }^{237} \mathrm{~Np}$ evaluation by Derrien is used in the current APOLLO2.8 library.

\section{Conclusion}

Target-accuracies on LWR parameters are 2-5 times lower than calculation uncertainties linked to nuclear data. Therefore, integral experiments are needed to meet design requirements. Specific facilities are needed for fundamental experiments, in order to check differential measurements of nuclear data against integral measurements. However, reduction of calculation errors requires:

- rigorous design of experiments (representativeness method),

- precise handling of technological uncertainties,

- accurate experimental techniques,

- Monte Carlo reference calculations and implementation of the V\&V\&Q method.

The trend analysis is the rigorous method to combine differential measurements and integral information. This powerful method enabled the derivation of reliable JEF2 modifications from Keff measurements and extensive Post-irradiation experiments. These trends were accounted for in the new JEFF3 evaluations; that allows the JEFF3.1 file [25] to be perfectly suited for industrial applications. Fundamental experiments, such as worth measurement of separated isotopes, are particularly efficient: they enable recent improvements and proposals for JEFF3.2 $\left({ }^{237} \mathrm{~Np},{ }^{239} \mathrm{Pu}\right)$. 


\section{References}

1. A. Santamarina, C. Collignon, C. Garat, French Calculation Schemes for Light Water Analysis, Proceedings of the International Conference on Reactor Physics PHYSOR'04, Chicago (USA), April 25-29 (2004).

2. A. Santamarina, C. Chabert, A. Courcelle, O. Litaize, G. Willermoz, D. Biron, L. Daudin, Qualification of the APOLLO2.5/CEA93-v6 Code for UOX and MOX fuelled PWRs, Proceedings of the PHYSOR-2002 International Conference on the New Frontiers of Nuclear Technology: Reactor Physics, Safety and High-Performance Comp., Seoul (Korea), Oct. 7-10 (2002).

3. V.V. Orlov, A.A. Van'kov, A.I. Voropaev, Yu.A. Kazanskij, V.I. Matveev, V.M. Murogov, E.A. Khodarev, At. Energy Rev. 18, 989 (1980).

4. S. Loubiere, R. Sanchez, M. Coste, A. Hebert, Z. Stankovski, C. Van Der Guth, I. Zmijarevic, APOLLO2 Twelve Years Later, Proceedings Int. Conf. Math. and Computation MECC'99, Madrid (Spain), September (1999).

5. C. Venard, A. Santamarina, A. Coulaud, D. Favet, Calculation error and uncertainty due to nuclear data. Application to MOX fissile media, Proceedings of ANS Meeting on Nuclear Criticality-Safety NCSD-2005, Knoxville, 19-22 Sept. (2005).

6. C. Chabert, A. Santamarina, D. Biron, C. Poinot, Qualification of the APOLLO2 assembly code using PWR-UO2 isotopic assays. The importance of irradiation history and thermo-mechanics on fuel inventory prediction, Proceedings of PHYSOR-2000 Int. Top. Meeting on Advances in Reactor Physics and Math., Pittsburg, USA, May 7-11 (2000).

7. D. Bernard, A. Santamarina, French Calculation Schemes for Light Water Analysis, Proceedings of the International Conference on Reactor Physics PHYSOR-2006, Vancouver (Canada), 11-14 Sept. (2006).

8. A. Santamarina, P. Albarede, P. Andrieu, J.P. Chauvin, F. Garcia, B. Gastaldi, B. Roque, Experimental Validation of Burn-up Credit Calculations by Reactivity Worth Measurements in the Minerve Reactor, Proceedings of Int. Conf. on Nucl. Criticality ICNC'95, Albuquerque (USA), 17-21 Sept. (1995).

9. J.-P. Hudelot, R. Klan, M. Antony, D. Bernard, P. Fougeras, F. Jorion, N. Drin, L. Donnet, C. Léorier, Preliminary Results of the OSMOSE Program for the Qualification of Integral Cross Section of Actinides in a PWR-UOx Core Configuration, Proceedings of the Int. Conf. PHYSOR-2006, Vancouver (Canada), 11-14 Sept. (2006).

10. Application of critical experiments and operating data to core design via formal methods of cross section data adjustment, Proc. of the NEACRP Specialists' Meeting, Jackson Hole, USA, Sept. 23-24 (1988), NEACRP-L-307.
11. A. Courcelle, A. Santamarina, JEF2.2 Nuclear data statistical adjustment using Post-Irradiation Experiments, Proceedings of the International Conference on Reactor Physics PHYSOR'04, Chicago (USA), April 25-29 (2004).

12. J. Blair Briggs (Ed.), International Handbook of Evaluated Criticality Safety Benchmark Experiments, NEA/NSC/DOC(95)03/I, Nuclear Energy Agency, September 2004 Edition, Paris (France).

13. C. Chabert, A. Santamarina, Trends in Nuclear Data derived from Integral Experiments in Thermal and Epithermal Reactors, Proceedings of ND2001 International Conference on Nuclear Data, Tsukuba (Japan), September (2001).

14. L.C. Leal, H. Derrien, N.M. Larson, R.Q. Wright, Nucl. Sci. Eng. 131, 230 (1999).

15. H. Derrien, A. Courcelle, L.C. Leal, A. Santamarina, Reevaluation and validation of Pu241 resonance parameters from thermal to $20 \mathrm{eV}$, Nucl. Sci. Eng.

16. H. Derrien, A. Courcelle, N. Larson, L.C. Leal, A. Santamarina, Evaluation of ${ }^{238} \mathrm{U}$ resonance parameters from 0 to $20 \mathrm{keV}$, Proceedings of ND2004 International Conference on Nuclear Data, Santa Fe (USA), 26 Sept.-1 Oct. (2004).

17. N. Thiollay, J.P. Chauvin, B. Roque, A. Santamarina, J.P. Hudelot, H. Toubon, Burn-up credit for fission product nuclides in PWR spent fuels, Proc. Int. Conf. on Nucl. Criticality ICNC'99, Versailles, 20-24 Sept. (1999).

18. A. Courcelle, O. Litaize, B. Roque, A. Santamarina, O. Serot, Experimental validation of main fission product and actinide nuclear data. Improvements for JEFF, Proceedings of PHYSOR2002 Int. Conference on the New Frontiers of Nuclear Technology, Seoul, Korea, Oct. 7-10 (2002).

19. Nakajima et al., Ann. Nucl. Energy 17, 569 (1990).

20. E. Dupont et al., Neutron evaluation and validation of Rhodium103, Proc. Int. Conf. on Nuclear Data for Science and Technology ND2004, Santa Fe (USA), 26 Sept.-1 Oct. (2004).

21. A. Courcelle, A. Santamarina, O. Serot, C. Chabert, B. Roque, Improvement of the BUC-FP Nuclear Data in the JEFF Library, IAEA-TECDOC, Technical Committee Meeting on Burn-up Credit Applications, TCM2002, Madrid (Spain).

22. D. Bernard, E. Fort, A. Courcelle, A. Santamarina, G. Noguere, ${ }^{239} \mathrm{Pu}$ Nuclear Data Improvement (this conference).

23. D. Bernard, A. Santamarina, ${ }^{237} \mathrm{~Np}$ Xs experimental validation. Proposal for JEFF3 modification, JEFDOC-1144, Paris 22-23 May (2006).

24. D. Bernard, O. Litaize, A. Santamarina, Actinide neutroninduced cross sections: Analysis of the OSMOSE LWR-UO2 experiment in MINERVE, Proceedings of the International Conference on Reactor Physics PHYSOR-2006, Vancouver (Canada), 11-14 Sept. (2006).

25. A. Koning, The JEFF Evaluated Nuclear Data Project (this conference). 